\title{
33. Predictions of Southern Pine Beetle Populations Using a Forest Ecosystem Model
}

\author{
Steven G. McNulty, Peter L. Lorio Jr., Matthew P. Ayres, and \\ John D. Reeve
}

Dendroctonus frontalis Zimm. (southern pine beetle (SPB)) has caused over $\$ 900$ million in damage to pines in the southern United States between 1960 and 1990 (Price et al.. 1992). The damage of SPB to loblolly (Pinus taeda L.), shortleaf (Pinus echinata Mill.), and pitch (Pinus rigida Mill.) pine has long been established (Hopkins. 1899), however, extensive mapping of SPB infestations has only existed since 1960 (Price and Doggett, 1982). Early detection of SPB outbreak areas is essential to controlling population increases (Swain and Remion, 1981), but the range of SPB is large, SPB have six to eight generations per year, and there is inconsistency in the monitoring methods used to measure SPB populations across its range. Therefore, various models have been developed that attempt to predict SPB outbreak severity across the region (Hansen et al., 1973; Kalkstein, 1974: Michaels. 1984).

In addition to predicting SPB outbreak areas based on present-day climates, models could be useful for assessing the influence of future climate change on SPB populations. One unknown regarding climate change and forest ecosystems involves the effect that chronically warmer air temperature could have on insect populations. For example, a $1{ }^{\circ} \mathrm{C}$ increase in average annual air temperature caused a tripling of a principal insect herbivore that feeds on mountain birch (Herms, 1991). When combined with the potential for increased forest stress resulting from climate change, increased insect populations could seriously reduce forest productivity across the region.

Because the SPB has six to eight generations per year, it is impossible to 
accurately measure the population at one time across a large geographic area. Instead, we have chosen to predict how average annual SPB populations change given annual environmental change. We have used a process-based forest water use and productivity model called PnET-IIS to assess the potential impact of climate change on average SPB population and southern pine forest growth. The PnET-IIS model has been used before to predict regional scale drainage, soilwater stress (WATSTRS), and forest productivity under historic conditions and for a series of climate change scenarios (McNulty et al., 1994, 1996a, 1996b, 1996c). This research modifies formerly validated predictions by PnET-IIS of forest water use and productivity to estimate factors associated with the regulation of average annual SPB populations, given historic climate data and two climate change scenarios. This type of model could be used to alert forest managers to present areas of heavy SPB infestation or future areas that are susceptible to infestation given changing climate.

\section{Factors Affecting Southern Pine Beetle Population}

White (1974) hypothesized that insect performance is favored in stressed plants because consumed tissues have higher nitrogen concentrations, and Rhoades ( 1979) linked increased stress with reduced synthesis of defensive compounds. It has long been recognized that climatic effects, especially drought can weaken host trees and increase SPB populations (Wyman, 1924; Craighead, 1925; St. George, 1930). Although the relationships between SPB population, climate, and host tree vigor have been studied and refined during the past seventy years, experimental evidence often fails to correlate increased plant stress with increased insect performance (Larsson, 1989) as fast-growing trees may also be at risk to SPB infestation (Hopkins, 1899; Lorio et al., 1988; Lorio and Sommers, 1986; Price et al., 1992). Manipulations of loblolly pine have also shown that severe water deficits can enhance the success of attacking SPB (Lorio and Hodges, 1977; Lorio et al., 1990), but these conditions may exceed normal climatic variation (Reeve et al., 1995). These findings and 450 other studies were summarized by Waring and Cobb ( 1992) in a review of plant interactions between plants and herbivores, and they concluded that climatic stress could have a positive, negative, or negligible influence on the size of insect populations.

The apparent discrepancy in correlating plant health, environmental stress, and insect population size arises because the interactions are complex and researchers lack the adequate knowledge of the causes of plant stress that is essential for understanding the nature of plant and insect interactions. For example, pine trees in the southeastern United States grow very rapidly in the spring and early summer but by midsummer, tree growth typically becomes limited by soil-water deficits (Reeve et al., 1995). This environmental change correspond to an ontogenetic transition in the cambium from the production of earlywood to latewood. The latewood is dominated by vertical resin ducts that function in the synthesis and transport of oleoresin (a mixture of monoterpenes and resin acids 
that impedes attacking bark beetles but also plays a role in secondary attraction of SPB). Annual variation in climatic conditions influences the timing of seasonal water deficits and the timing of the transition from earlywood to latewood. Measurements of resin flow from standardized wounds to the face of the cambium indicate that spring and early summer is a period of low resin flow for loblolly pine. The transition to latewood formation is accompanied by an increase in resin flow. probably resulting from the increase in vertical resin ducts and because increased water stress would increase the production of secondary metabolites. A climate that protracts the period of earlywood production in southern pine (e.g., high precipitation in midsummer) favors SPB outbreaks by extending the time when trees are more easily colonized. To better predict the effects of SPB on forest function and changes in SPB populations size, improved physiologically based forest-process models are needed.

\section{Modeling Southern Pine Beetle Populations}

Many insect population models have attempted to correlate outbreaks of SPB with climatic conditions, including principle component analysis (Michaels, 1984; Michaels et al., 1986) but have had limited success (Hansen et al., 1973; Kalkstein, 1974). One reason for the lack of success in relating SPB activity to climate may be that other factors (e.g., oleoresin production, prior years' SPB population, growth and differentiation balance relationships) that are needed to predict SPB population changes are often not included in predictive models (Martinat, 1987). For example, Michaeis et al., ( 1986) developed a model (SPBCMP) that incorporates climate and site-specific volume and growth data into predictions of future SPB population size. Although this model has many biological controls that have been cited as factors regulating SPB population size, the model makes many assumptions about forest processes that could be better simulated using a forest process model such as PnET-IIS. A better estimate of forest function would improve a model's ability to accurately predict changes in the average annual SPB population size.

\section{Original PnET-IIS Model Structure and Predictive Outputs}

To predict and project average annual SPB populations we used PnET-IIS ( McNulty et al., 1994, 1996a, 1996b), a monthly time-step model, which is a derivation of the PnET-II model developed by Aber and Federer ( 1992) and Aber et al., (1995) for predicting forest water use and productivity. The PnET-IIS model has been modified to run for pine forests across the southern United States. The model uses site-specific, soil-water-holding capacity, four monthly climate parameters (i.e., minimum and maximum air temperature, total precipitation, and solar radiation) and species-specific process coefficients to predict evapotranspiration (ET), water drainage, soil water stress (WATSTRS), and net primary productivity (NPP) from the stand level (< one hectare (ha)) to a 0.5 " $\times 0.5$ " grid 
cell resolution (approximately $50 \times 75 \mathrm{~km}$ ) across the southern United States (Mc Nulty et al.. 1994, 1996b).

Leaf area is a major component in calculating NPP, plant-water use and soilwater stress. The PnET-IIS model assumes that all stands are fully stocked and that leaf area is equal to the maximum amount of foliage that can be supported by soil. climate, and vegetative conditions. Predicted NPP is total gross photosynthesis minus growth respiration and maintenance respiration for leaf, wood, and root compartments. The model calculates respiration as a function of the present and prior month's minimum and maximum air temperature. The optimum temperature for loblolly pine net photosynthesis varies from 23 to $27^{\circ} \mathrm{C}$, and the maximum air temperature for gross photosynthesis ranges from 30 to $43{ }^{\circ} \mathrm{C}$ (Strain et al., 1976). As temperature increases beyond the optimum photosynthetic temperature, the respiration rate increases while gross photosynthesis increases slightly or decreases, so that a proportionally reduced amount of net carbon per unit leaf area is fixed (Kramer, 1980). Total gross photosynthesis is a function of gross photosynthesis per unit leaf area and total leaf area. Changes in water availability and plant-water demand place limitations on the amount of leaf area produced. When vapor pressure is deficient and air temperature increases, leaf area and total gross photosynthesis decrease.

Annual transpiration is calculated from a maximum potential transpiration that is modified by plant-water demand (a function of gross photosynthesis and water use efficiency (WUE)). Interception water loss is a function of leaf area and total precipitation; in closed canopy stands, interception water loss is approximately $15 \%$ of total precipitation. Evapotranspiration is equal to transpiration and interception loss, and drainage is calculated as water in excess of ET and soil-waterholding capacity (SWHC). Plant-water demand is dependent on monthly precipitation and water stored in the soil profile. If precipitation inputs exceed plantwater demand, the soil is first recharged to the SWHC, and if water is still available, it is output as drainage. Monthly drainage values are summed to provide an estimate of annual water outflow. Present-year growing season (April to September) soil water stress (WATSTRSO) equals $0.15+(1 \quad$ (average growing season soil water/SWHC). Average growing-season soil water equals the sum of monthly calculated growing-season soil water that is $<$ SWHC, divided by the number of months in the growing season. Theoretically, soil water stress could range from 0.15 (no water stress) to 1.15 (maximum potential water stress); and has a minimum value 0.15 , as opposed to 0 , to reflect approximate percentage of hygroscopic water present in southern clay soils that cannot be removed by plant roots (Pritchett, 1979). Therefore, if no precipitation occurred during the growing season, soil water stress would be 1.15. Across the southern United States, average annual WATSTRS range between 0.15 and 0.50 .

At a prior date, PnET-IIS model predictions of water use and productivity have been validated across the southern United States. Stream-gauge stations represent an integration of water yield across a region. Predictions of drainage across the southern United States by PnET-IIS were well correlated with average US Geological Survey measured discharge from 1951 to $1980\left(R^{2}=0.66\right.$, 
$\mathrm{P}<0.00001, \mathrm{n}=502$ ) (McNulty et al., 1996a). Predicted NPP was also well correlated with measured average annual basal area growth in twelve sites located from Texas to Virginia $\left(\mathrm{R}^{2}=0.67 . \mathrm{P}=0.005, \mathrm{n}=12\right)($ McNulty et al., 1996a).

\section{Southern Pine Beetle Population Modeling Using PnET-IIS}

Although many researchers have attempted to relate climatic factors with tree stress and SPB population change. most have had little success, However, oleoresin production has been linked with the failure rate of SPB to colonize host trees and, hence, is a partial controller of average annual SPB population size (Lorio, 1986; Reeve et al., 1995). Factors that regulate oleoresin production (i.e., soil water stress and photosynthesis) should, therefore, also partially affect SPB population size. In addition to tree stress, SPB population size is quasicyclic (Turchin et al.. 1991), therefore the size of the prior year's SPB population is also an important factor in deciding the size of the present year's SPB population. These three factors (soil water stress, photosynthesis, and the prior year's SPB population) all influence the present year's SPB population and will be discussed in later sections.

The PnET-IIS is primarily a regional scale, forest-process model, and the model is not designed to predict some parameters that are important in forecasting SPB at the stand level. For example, PnET-IIS simulates stand growth from time zero to a point of canopy closure. Canopy closure and model equilabration requires approximately ten years of data. No provision is made for stand age or stand stocking because it would be impractical to input this information into the model on a regional scale. However, both stand stocking and forest age are important controllers of SPB infestation rates.

\section{Soil Water Stress}

Total oleoresin production is partially a function of plant-growth-differentiation balance, which is related to soil water stress. The principle of growth-differentiation balance asserts that tissue growth is negatively associated with tissue differentiation when the two processes compete for the same pool of carbohydrates (Loomis, 1932, 1953; Lorio, 1986, 1988; Herms and Mattson, 1992). Plants with a surplus of carbohydrates beyond that which can be invested in growth because of such limitations as soil water stress, invest proportionally more carbon in differentiation of such secondary compounds as oleoresin, which would be detrimental to such insect herbivores as the SPB. Conversely, plants limited in carbon supply invest less carbon into growth or differentiation processes. Plants with a high allocation to differentiation should have low concentrations of water and protein, but high concentrations of such secondary metabolites as oleoresin (Herms and Mattson, 1992).

Oleoresin production and growth-differentiation balance can be modeled using an inverse hyperbolic function of soil water stress (Reeve et al., 1995). In southern pines, although growth processes decline during moderate soil-water deficits, the production of secondary compounds tends to increase. When soil water stress is 
low. more of the photosynthate is devoted to tree growth compared to oleoresin production. Conversely, when soil water stress is very high (i.e., extreme drought) the production of photosynthates will be low because stomates remain closed and total photosynthate and oleoresin production remains low. Therefore, during periods of moderate water stress, pines may be less susceptible to SPB attack than during periods of either very low or high water stress. The PnET-IIS model uses an inverse hyperbolic function of soil water stress factor (WATSTRSFAC) to simulate the effect of soil water stress on oleoresin production (Figure 33.1). When soil water stress was either low or high, oleoresin production was low and WATSTRSFAC $>1.0$; when soil water stress was moderate, oleoresin production was maximized and WATSTRSFAC $\leq 1.0$. The relationship between oleoresin production and the probability of SPB colonization is expressed as the effect that present-year oleoresin production (WATSTRFACO) would have on present-year

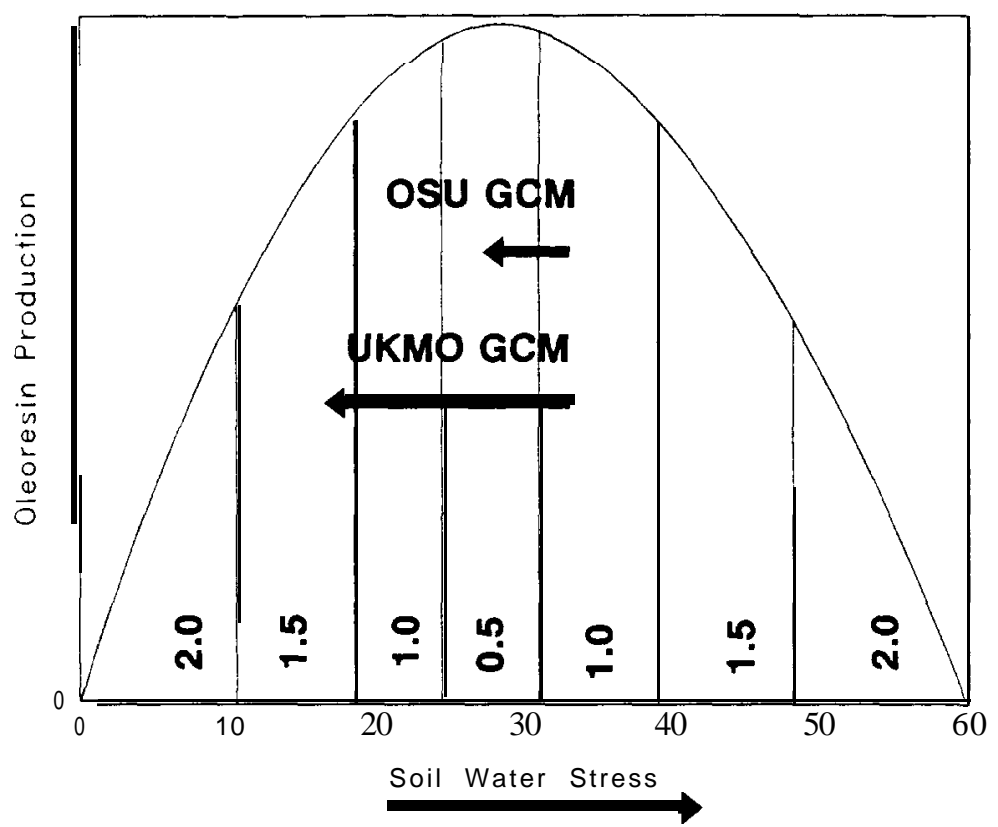

Figure 33.1. The influence of soil-water stress (WATSTRS) on oleoresin production is represented by an inverse hyperbolic function, and is expressed as a southern pine beetle population multiplication factor (WATSTRSFAC). Maximum oleoresin production and the maximum reduction in the WASTRSFAC (WASTRSFAC $=0.5$ ) occurs under conditions of moderate soil water stress. Extreme water stress or extreme water excess reduces oleoresin production and increases the WASTRSFAC (WASTRSFAC $>$ I .0). Under historic conditions, the ecosystem predicted moderately severe water stress and WASTRSFAC $=1.0$. Both the Oregon State University (OSU) and United Kingdom Meteorological Office (UKMO) caused a predicted decrease in regional soil water stress resulting from a reduction in total leaf area and a decrease in plant-water demand across the southern United States. 
average SPB population size (SPBPOP0). The WATSTRFACO values $>1.0$, $=1$.O. and $<1$.O show that conditions are more favorable, equally favorable, or less favorable to future SPB populations, compared to the present-year average SPB popuiation size.

\section{Photosynthesis}

The rate of plant photosynthesis also affects oleoresin production (Reeve et al., 1995). Although related to soil water stress, photosynthesis is also a function of air temperature and species type. Across the region, predicted average historic annual NPP is approximately $12 \mathrm{t}$ ha ${ }^{1}$ year- ${ }^{1}$ (McNulty et al., 1996b). If NPP were the only factor controlling oleoresin production, rapidly growing trees should have lower oleoresin production and higher incidence of SPB infestation compared to slower-growing trees. When rates of photosynthesis are low, little carbohydrate is available for growth or production of secondary compounds and when photosynthesis is high much more carbohydrate is available, but proportionally less of the carbohydrate may be allocated for secondary compounds (Reeve et al., 1995). Finally, when photosynthetic rates are moderate, much of the photosynthate that is being produced is devoted to such secondary compound production as oleoresin (Ayres, 1995). For this model, NPP will be used as an indicator of changes in photosynthesis and total photosynthate production. Similar to soil water stress, net primary productivity factor (NPPFAC) represents the inverse hyperbolic function between NPP, oleoresin production, and average annual SPB population size. which is related using changes in the SPB population size multiplication fraction (Figure 33.2). Present-year NPP $>10$ t ha- 'year- 1 or $<8$ t ha- ' year- I has a NPPFAC $>1$, while NPP $<10 \mathrm{t} \mathrm{ha}^{-1}$ year-1 and $>8 \mathrm{t} \mathrm{ha}^{-1}$ year-' has a NPPFAC $<1.0$.

\section{Prior Year's Southern Pine Beetle Population Size}

No matter how idyllic environmental and plant conditions are for the reproduction of SPB, outbreaks of SPB cannot occur without a pre-existing SPB population. Additionally, the larger the size of the present SPB population, the greater the potential to colonize new areas and thus increase the size of the future SPB population further. Conversely, however, under these same conditions, natural SPB enemy populations could also build up, and therefore reduce the SPB population. A relative measure of the prior year's average SPB population is the final equation factor used to calculate a relative measure of the present year's average SPB population. Population data can either be collected from the agencies that monitor SPB numbers or if multiple years of prediction are needed, prior years' predicted average annual SPB population data can be used. Although the insects may follow a cyclic pattern, other factors (e.g., climate, parasites, predators, or disease) could delay or accelerate the average annual population flux. This theory of density dependence is the basis of the Turchin et al., (1991) research on reasons for SPB population fluctuations. Using the average number of SPB spots in eastern Texas from 19.55 to 1985 , Turchin et al., (1991) found a significant lag 


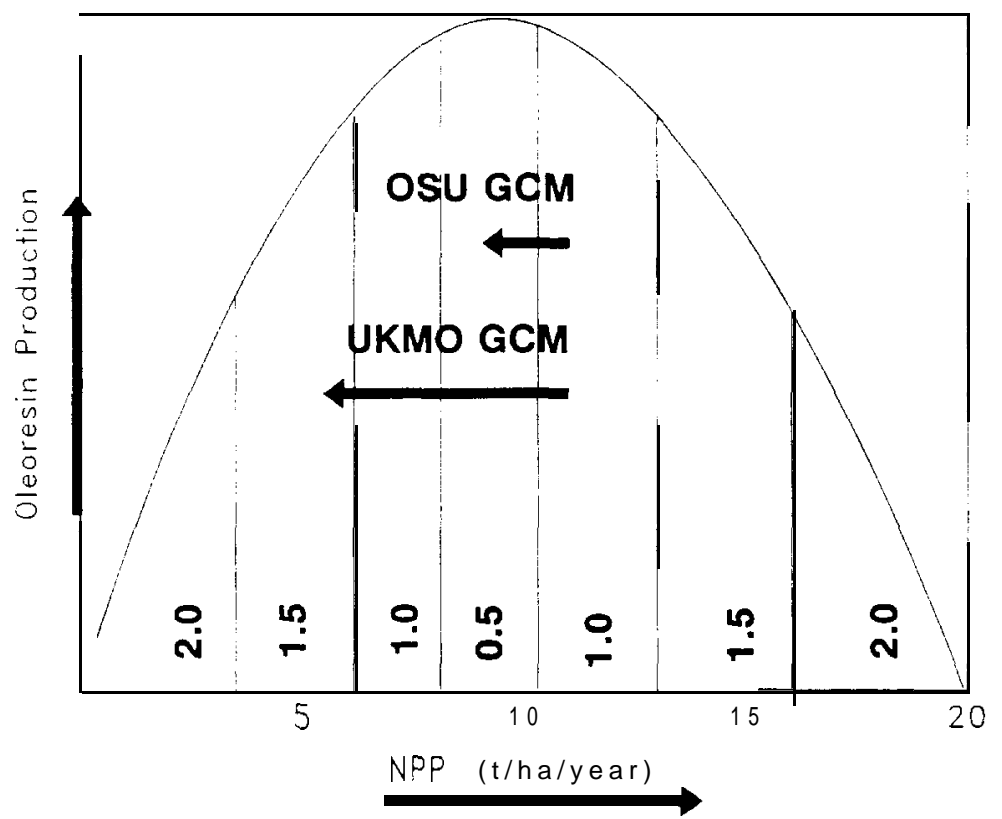

Figure 33.2. The influence of net primary productivity (NPP) on oleoresin production is represented by an inverse hyperbolic function, and is expressed as a SPB population growth multiplication factor (NPPFAC). Maximum oleoresin production and the maximum reduction in the SPB population factor $(\mathrm{NPP}=0.5)$ occurs under conditions of moderately limited NPP. Extreme reductions or increases in NPP reduce oleoresin production and increases the SPB population factor (NPPFAC >1.0). Under historic conditions, the ecosystem predicted moderately high rate of NPP and WASTRSFAC $=1.0$. Both the Oregon State University (OSU) and United Kingdom Meteorological Office (UKMO) caused a decrease in NPP resulting from a reduction in total leaf area and decrease in net carbon fixed per unit of leaf area.

affect between the average present and prior year's SPB population size, and they did not detect any correlation between climate change and the rate of SPB population change. However, they did not examine the relationship between climate and vegetative response. Although Turchin et al., ( 199 1) did not determine any cause for the cyclic nature of SPB populations, prior years' SPB population size were clearly related to the present year's population size.

\section{Combining Factors in PnET-IIS}

Predictions of average annual SPB populations were based on predicted changes in growing season WATSTRS, NPP (NPPFAC), and measured or predicted prior years' average SPB population size (SPBPOP). Although WATSTRS and NPP affect the oleoresin production that result from changes in total carbohydrate 
production and carbon partitioning patterns, and thus, the environmental conditions for SPB colonization and reproduction. the SPBPOP determines the starting condition for future changes in average annual SPB populations.

Turchin's theories on prior year's average SPB populations (SPBPOPI) controlling present-year average SPB population (SPBPOPO) were evenly weighted with the present-year's WATSTRSFACO and NPPFACO to produce a relative prediction of the present-year's average SPB population (SPBPOPO) as shown:

$$
\text { SPBPOPO }=\text { WATSTRSFACO } \times \text { NPPFACO } \times \text { SPBPOP } 1
$$

Average southern pine beetle populations were also predicted using prior year's soil water stress (WATSTRSFAC 1), NPP (NPPFAC1), and average annual SPB population data (SPBPOP1) as follows:

$$
\text { SPBPOPO }=\text { WATSTRSFAC } \mid \times \text { NPPFAC } 1 \times \text { SPBPOP I }
$$

Csing the second-year's prior WATSTRS (WATSTRSFAC2), NPP (NPPFAC2), and average annual SPBPOP size (SPBPOP2), is shown as:

$$
\text { SPBPOPO }=\text { WATSTRSFAC } \times \text { NPPFAC2 } \times \text { SPBPOP2 }
$$

\section{Input Data}

The PnET-IIS model uses constant, generalized, species-dependent process parameters (e.g.. light extinction coefficient, and optimum temperature for gross

\begin{tabular}{|c|c|c|}
\hline Parameter & $\begin{array}{l}\text { Parameter } \\
\text { abbreviation }\end{array}$ & Model value \\
\hline Light extınction coefficient & $\mathrm{k}$ & 0.5 \\
\hline Foliar retention time (years) & & $2.0^{*}$ \\
\hline Leaf specific weight $(\mathrm{g})$ & & $9.0^{*}$ \\
\hline NetPsnMaxA (slope) & & $2.4^{*}$ \\
\hline NetPsnMaxB (intercept) & & $0^{*}$ \\
\hline Light half saturation $\left(\mathrm{J} \mathrm{m}^{2} \mathrm{sec} \quad 1\right)$ & $\mathrm{HS}$ & 70 \\
\hline Vapor deficit efficiency constant & VPDK & 0.03 \\
\hline Base leaf respiration fraction & & 0.10 \\
\hline Water use efficiency constant & WUE C & 10.9 \\
\hline Canopy evaporation fraction & & 0.15 \\
\hline Soil-water release constant & F & 0.04 \\
\hline Maximum air temperature for photosynthesis ("C) & TMAX & variable* \\
\hline Optimum air temperature for photosynthesis ("C) & TOPT & variable* \\
\hline Change in historic air temperature ("C) & DTEMP & 0 \\
\hline Change in historic precipitation (\% difference) & DPPT & 0 \\
\hline
\end{tabular}
photosynthesis) (Table 33.1) and site-specific soils and climate data. Soils series

Table 33.1. PnET-IIS Model Values

* Values are denved specifically for loblolly pine. All other parameters are general vegetative values. 
data were derived from a geographic information system (GIS)-based soils atlas compiled by the Soil Conservation Service (Marx, 1988). The soil series data was hand-digitized from a paper source at a scale between 1:500,000 and 1: 1,500,000, depending on the state (Marx. 1988). Soil information associated with each series includes soil water holding capacity (SWHC) to a depth of $102 \mathrm{~cm}$, which is the only site-specific soils data used in our simulations. All other soils parameter values were held constant across all sites and years (Table 33.1). The PnET-IIS model also requires four monthly climatic drivers, which are 1) minimum air temperature, 2) maximum air temperature, 3) precipitation, and 4) solar radiation. The Forest Health Atlas provided cooperator and first-order station data. which was originally obtained from the National Climatic Data Center (NCDC) (Marx, 1988). Cooperator station data include average minimum and maximum monthly air temperature and total monthly precipitation; first-order station records include relative humidity. Because these data had error rates between 5 and 40\% (Marx, 1988), much of the data was removed before usage. After checking for accuracy, the database was interpolated on a $0.5 " \times 0.5$ " grid across the southern United States (Marx, 1988). The gridded databases of minimum and maximum air temperature, relative humidity and precipitation were compiled into a single database and run through a program to calculate monthly solar radiation (Nikolov and Zeller, 1992) at a 0.5 " x 0.5 " grid. Solar radiation values were then combined with average monthly maximum and minimum air temperature and total monthly precipitation and put into PnET-IIS.

\section{A Case Study in Southern Pine Beetle Population Size Modeling}

As an example of SPB population modeling, we predicted average annual SPB population changes for Walker County in Texas. This county was selected because this is an area with a variable SPB population that has been summarized at a prior date (Turchin et al., 1991). We obtained twelve years of climate, soils, and SPB population datal for this area, and then used PnET-IIS to predict how average SPB population size would change over time given changes in WATSTRS, NPP, and the prior year's average SPB population size.

Predicted changes in the average SPB population using the equation (1) were highly correlated with measured average $S P B$ population $\left(R^{2}=0.76, P=0.0004, n\right.$ = 12). If predictions of present average SPB populations (SPBPOPO) were based on the prior year soil water stress (WATSTRSFAC1), NPP (NPPFAC1) factors, and the prior year's average SPB population (SPBPOP 1), without any knowledge of present year soil water stress or NPP (equation 2), the correlation is weaker but still significant $\left(\mathrm{R}^{2}=0.47, \mathrm{P}=0.016, \mathrm{n}=12\right)$. Environmental stress from the present and prior year are the controlling factors of present year average SPB populations, as no relationship $(\mathrm{P}>0.05)$ was found with environmental stress

SPBPOP data supplied by R.F. Billings. 
from the two prior years (WATSTRS2, NPPFAC2, and SPBPOP2), and the present year's average SPB population (equation 3). The PnET-IIS model may predict SPB populations better than other SPB population models because climate and soils are linked to form a better measure of ecosystem function compared to using a coarse measure of such ecosystem stress as precipitation or days over $90^{\circ} \mathrm{F}$.

\section{Projections of Climate Change Effects on Southern Pine Beetle Populations}

ln addition to predicting present-year average SPB populations, PnET-IIS could also be used to predict how climate change may affect future SPB populations, General circulation models (GCMs) estimate a 3 to $7{ }^{\circ} \mathrm{C}$ increase in annual air temperature by the year 2050 across the southern United States (Cooter et al., 1993). Although most of the major GCM scenarios predict a total annual precipitation change of $<10 \%$, the timing of the precipitation could be markedly altered from historic patterns (Cooter et al., 1993). These changes could significantly influence the severity and frequency of SPB outbreaks. Such models as $\mathrm{PnET}$-IIS could be used to predict changes in future SPB populations given present-day climate or future climate change scenarios.

Two climate change scenarios were developed using historic climate databases with two GCMs. The GCMs from both Oregon State University (OSU) (Schlesinger and Zhao, 1989), and United Kingdom Meteorological Office (UKMO) (Mitchell, 1989) were selected because of their common application and range of climate change predictions. All of the GCMs predict variation in monthly temperature and precipitation, based on a doubling of atmospheric carbon dioxide (CO,) by 2050 (Cooter et al., 1993). Grid data from each of the two GCMs monthly climate change databases were added to historic (from 1950 to 1985) average monthly minimum and maximum air temperature or were multiplied by historic monthly precipitation to produce thirty-five years of climate change scenario data. The predictions by GCMs of precipitation and air temperature under a doubled CO, environment vary widely. Across the southern United States, the OSU GCM consistently predicted smaller increases $(+3$ " C) in average annual air temperature compared to the UKMO GCM ( +7 "C). The OSU GCM predicted above-average precipitation in the late summer and fall, and below historic average levels of precipitation in the late winter and spring. The OSU GCM also predicted that total annual precipitation would decrease in the central portion of the South and increase along the Atlantic coast although region-wide, average annual precipitation would increase by $3 \%$ compared to historic total annual precipitation. The UKMO GCM predicted that regional precipitation would be greater than historic amounts during the spring and less during the summer and fall. Average annual precipitation would decrease in the central and southwestern portion of the region and increase along the southern Atlantic coast, and total 
annual precipitation would decrease by $1 \%$ region-wide when compared to historic levels.

\section{Climate Change Scenario Effects on Net Primary Productivity}

When PnET-IIS was run with the two climate change scenarios. predicted NPP was reduced across most of the southern United States (except in some highelevation, mountainous areas) but the severity of the reductions were dependent on the GCM applied. Using the OSU GCM scenario, PnET-IIS predicted a reduction in growth across most of the southern United States, but these growth reductions were generally not severe enough to cause tree death or large reductions in species range. The PnET-IIS model predicted that approximately $2 \%$ of the present loblolly pine range would be lost across the southern United States if the OSU GCM scenario occurred, and that NPP would generally decrease across the region but could increase in the cooler mountain areas (Figure 33.3b) compared to historic rates on NPP (Figure 33.3a).

In the UKMO GCM scenario, predicted NPP would be reduced by $100 \%$ of historic NPP across most of the southcentral and southwestern portions of the region including most of Florida, Georgia, Alabama, Mississippi, Louisiana, and Texas (Figure 33.3c), suggesting that the climate in these states would no longer be suitable for growing loblolly pine. The UKMO GCM predicted less severe reductions in NPP for the northern and eastern portions of the region (Figure $33.3 \mathrm{c}$ ), because areas had historically cooler air temperatures and high rates of precipitation. Average regional NPP was reduced by $46 \%$ and the range of loblolly pine was reduced by $42 \%$ when the UKMO GCM scenario was applied to the model (Figure 33.3c).

\section{Climate Change Scenario Effects on Soil Water Stress}

Because drainage is equal to precipitation-ET, and ET and NPP are functions of leaf area and temperature, the pattern of drainage is similar to NPP. Using the OSU GCM, predicted WATSTRS increased in the central and northcentral areas, and decreased across the southern and eastern portions of the region (Figure 33.4b), compared to historic WATSTRS (Figure 33.4a). The scenario from OSU also predicted that average annual WATSTRS would decrease by $22 \%$ across the region (Figure 33.4). Compared to the OSU GCM scenario, the UKMO GCM scenario caused a larger deviation in predicted ecosystem WATSTRS. In areas of mortality, predicted ET was zero, drainage was equal to precipitation, and WATSTRS was a function of precipitation. The UKMO scenario predicted decreased WATSTRS throughout the region, except along the cooler Appalachian Mountains where WATSTRS would increase (Figure 33.4c). Compared to historic WATSTRS, the UKMO scenario average annual WATSTRS decreased by $56 \%$ across the region. If only areas where loblolly pine NPP $>0$ are included, WATSTRS decreased by only $27 \%$ compared to historic levels. 


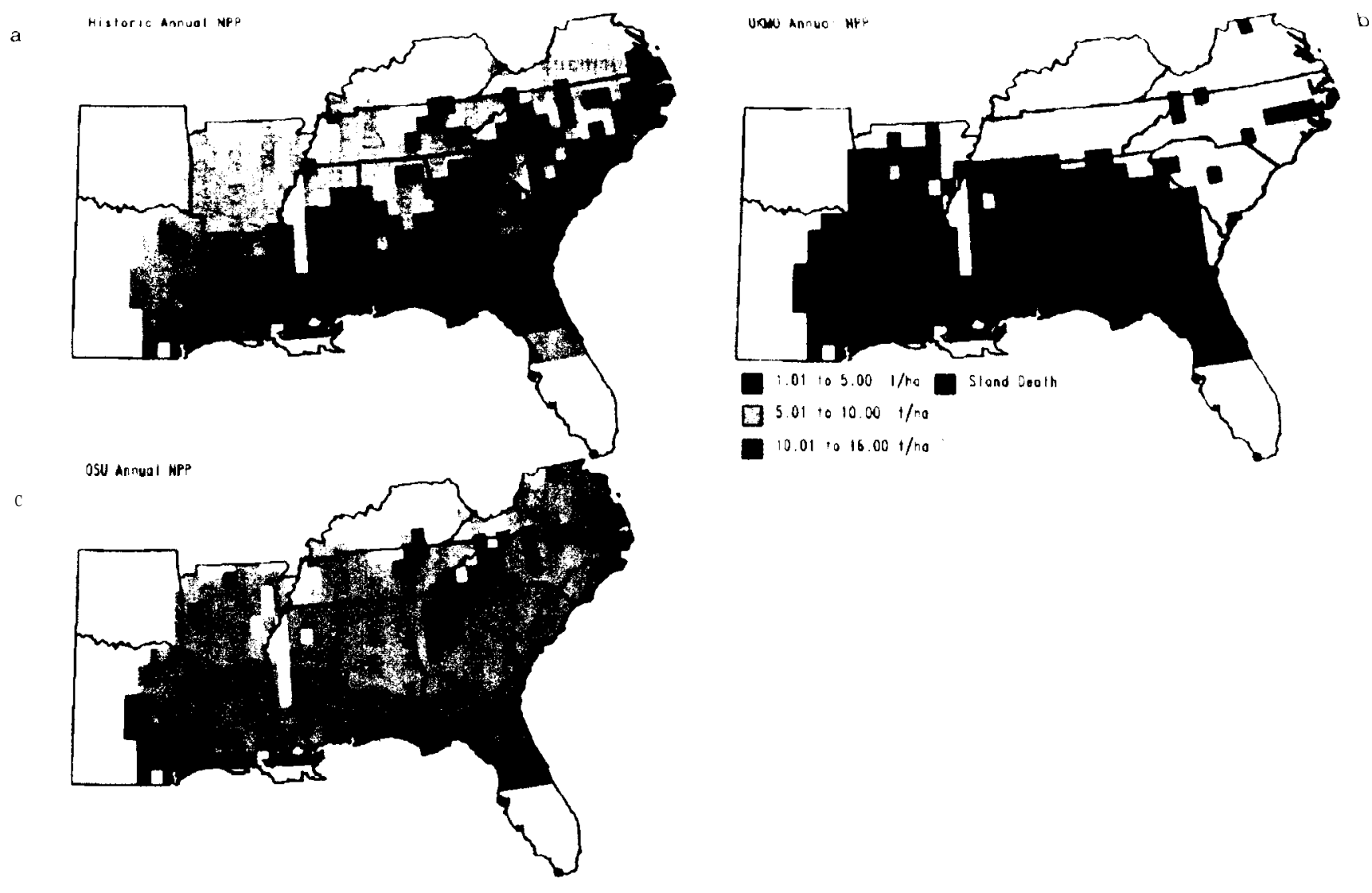

Figure 33.3. Regional changes in net primary productivity (NPP) across the southern United States for: historic (from 1951 to 1984) climate (a); the Oregon State University, general circulation model (GCM) scenario (b); and the United Kingdom Meteorological Office GCM scenario (c). 
0
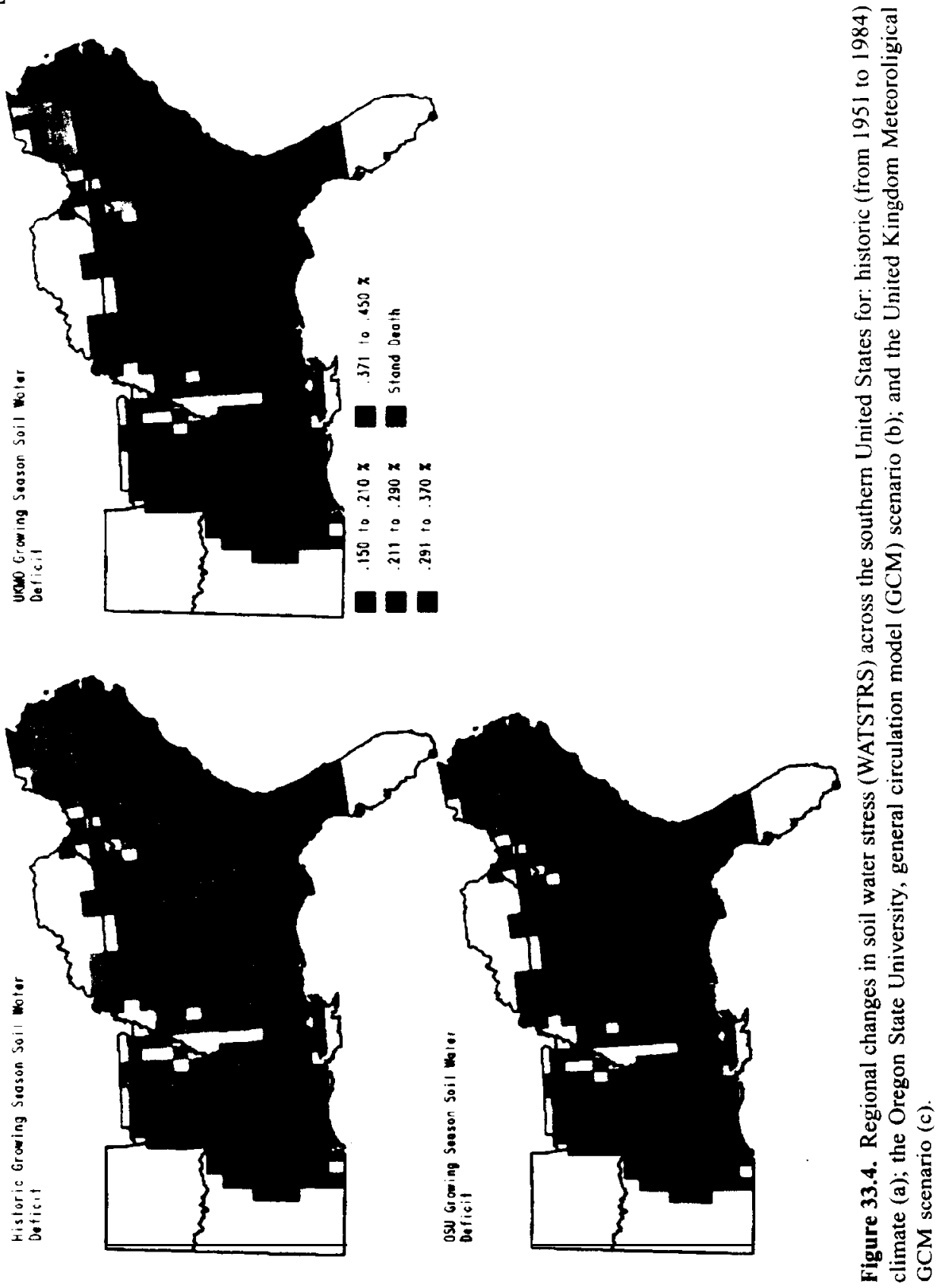


\section{Effects of Changing Soil-Water Stress and Net Primary Productivity on Southern Pine Beetle Populations}

Lnder conditions of climate change. average annual NPP and soil water stress will generally decrease across the region (Figures 33.1 and 33.2). With a reduction in NPP and ET. total plant-water demand will also decrease. As soil water stress decreases, pines across the south may become less water limited and more temperature limited. In the UKMO scenario, increased air temperatures reduced NPP and the plants become carbon limited. If carbon limitations become severe, oleoresin synthesis will probably also decline (Ayres, 1993) and SPB populations could rapidly increase. The OSU scenario projects less severe changes in climate and. therefore, less severe changes in forest ecosystem processes. Slight reductions in the NPP and soil water stress across the region under the OSU scenario could increase oleoresin production and therefore. cause a reduction in average annual SPB populations (Figures 33.1 and 33.2). Although the model predicts that within the region, certain areas could see NPP increases (e.g., Appalachian Mountains) or increased soil water stress (Figures 33.3 and 33.4), causing little or no change in average annual SPB populations, such areas as eastern Texas or central Florida could have large reductions in NPP and soil water stress and oleoresin production, leading to increases in the predicted average annual SPB population.

The size of these decreases will vary with year, and extreme event years will probably have a much greater impact on forest mortality than long-term averages. To better understand the potential effects of climate change on average annual SPB populations, individual years and locations need to be examined.

\section{Model Refinement}

The present version of the model only predicts SPB populations at an annual time step. Because PnET-IIS predicts water use and productivity at monthly intervals, future versions of the model could have increased sensitivity for predicting SPB populations if a finer temporal resolution were used. Reeve et al., (1995) noted that in the southeastern United States, pine trees grow very rapidly in the spring and early summer and vertical resin ducts are absent or rare (earlywood growth). By midsummer, tree growth generally slows resulting from soil-water deficits and the latewood formed typically contains many resin ducts. The timing of the transition from earlywood to latewood formation has significant impact on tree resistance to insect herbivores. Climatic patterns that protract the length of earlywood development favor SPB attack and, therefore, monthly predictions of WATSTRS and NPP may be better predictors of changing SPB populations compared to growing-season averages. Future SPB population models should attempt to incorporate monthly variation in forest processes into model predictions of SPB population change. 


\section{Conclusions}

Initial efforts to correlate the present and prior year's soil water stress and NPP, and the prior year's average SPB population with present-year average annual SPB population have proven moderately successful. This success has lead to the attempt to predict how potential future climate change could affect future SPB populations. Depending on the climate scenario and site location. southern pine NPP and soil water stress could be significantly reduced across forested areas in the southern United States. Sites located in the warmest sections of the present pine range are more sensitive to changes in climate than are pine sites located in drier or cooler areas. These predictions also suggest that the region is much more susceptible to changes in air temperature than changes in precipitation. If our model predictions are correct, climate change would have serious potential socioeconomic implications for the southern U.S. timber industry. However, additional research is needed to assess the effects that other atmospheric changes (e.g., $\mathrm{CO}_{2}$, $\mathrm{O}_{3}, \mathrm{NO}, \mathrm{SO}$,), genetics, and species replacement may have on forest processes, before a complete assessment of climate change effects on forest productivity, water use and SPB populations can be made.

\section{References}

Aber JD, Federer CA 1992 A generalized, lumped-parameter model of photosynthesis, evapotranspiration and net primary production in temperate and boreal forest ecosystems, Oecologia, 92:463-474.

Aber JD, Ollinger SV, Federer CA, Reich PM, Goulden ML, Kicklighter DW, Melillo JM, Lathrop RG Jr. Ellis JM. (1995) Predicting the effects of climate change on water yield and forest production in the northeastern U.S. Climate Res 5:207-222.

Ayres MP ( 1993) Plant defense, herbivory, and climate change. In Kareiva PM, Kingsolver JG. Huey RB (Eds) Biotic interactions and global change. Sinauer Associates, Sunderland, MA.

Cooter EJ, Eder BK, LeDuc SK, Truppi L 1993 General circulation model output for forest climate change research and application. Gen Tech Rep SE-85. USDA, For Ser, Southeast For Exper Stat. Asheville, NC.

Craighead FC (1925) Bark beetle epidemics and rainfall deficiency. J Econ Entomol 18:577-584.

Hansen JB, Baker BH, Barry PJ (1973) Southern pine beetles on the Delaware Peninsula in 1971. J Ga Entomol Soc 8:3:157-164.

Herms DA ( 1991 ) Variation in the resource allocation patterns of paper birch: Evidence for physiological tradeoffs among growth, reproduction, and defense. PhD dissertation. MI State Univ, East Lansing.

Herms DA, Mattson WJ (1992) The dilemma of plants: To grow or defend. Q Rev Biol $67: 283-335$.

Hopkins AD (1899) Report on investigations to determine the cause of unhealthy conditions of the spruce and pine from 1880-1893. WV Agri Exper Stat Bull 56, 461.

Kalkstein LS ( 1974) The effect of climate upon outbreaks of the southern pine beetle. Publ Climatol 27: 1-65.

Kramer PJ (1980) Drought, stress and the origin of adaptations. Adaptation of plants to water and high temperature stress. John Wiley and Sons, New York.

Larsson S (1989) Stressful times for the plant stress-insect performance hypothesis. Oikos 56:277-283. 
Loomis WE 11932) Growth-differentiation balance vs. carbohydrate-nitrogen ratio. Proc Am Soc Hortic Sci 29:240-245

Loomis WE (1953) Growth correlation, In Loomis WE (Ed), Growth and differentiation in plants. I.4 State Coll Press. Ames, Iowa.

Lurio PL Jr (1986) Growth-differentiation balance: A basis for understanding southern pine beetle-tree interactions. For Ecol Manage 14:259-273.

Lorto PL Jr I 19881 Growth-differentiation balance relationships in pines affect their resistance to bark beetles (Coleoptera: Scolytidae). In Mattson WJ. Levieux J, BernardDagan ( (Eds). Mechanisms of woody plant detenses against insects. Springer-Verlag, Vew York.

Lorlu PL Jr. Hodges JD ( 1977) Tree water status affects induced southern pine beetle attack and brood production. US For Serv Res Pap SO-135.

Lono PL Jr, Sommers RA (1986) Evidence of competition for photosynthates between growth processes and oleoresin synthesis in Pinus taeda L. Tree Physiol 2:30 I _ 306.

Lor1o PL Jr. Sommers RA, Blanche CA. Hodges JD, Nebeker TE (1990) Modeling pine resistance to bark beetles based on growth and differentiation balance principles. In Dixon RK. Meldahl RS, Ruark GA. Warren WG (Eds). Process modeling of forest growth responses to environmental stress. Timber Press, Portland OR.

Martinat PJ ( 1987) The role of climatic variation and weather in forest insect outbreaks. In Barbosa P. Schultz JC (Eds). Insect outbreaks. Academic Press, San Diego, CA.

Marx DH ( 1988 ) Southern forest atlas project. In The 81st annual meeting of The Associaton Dedicated to Air Pollution Control und Hazardous Waste Management (APCA). Dallas. Texas. 1988.

McNulty SG. Vose JM, Swank WT. Aber JD. Federer CA (1994) Landscape scale forest modeling: Data base development, model predictions and validation using a geographic information system. Clim Res 4:223-231.

McNulty SG, Vose JM, Swank WT (1997) Scaling predicted pine forest hydrology and productivity across the southern United States. In Quattrochi DA. Goodchild ME (Eds) Scaling in remote sensing and GIS. Lewis Publishers. Chelsea, MI.

McNulty SG. Vose JM, Swank WT (1996a) Loblolly pine hydrology and productivity across the Southern United States. For Ecol Manage 86:241-251.

McNulty SG, Vose JM, Swank WT (1996b) Potential climate change affects on loblolly pine productivity and hydrology across the southern United States. Ambio 25(7):449453.

Michaels PJ ( 1984) Climate and the southern pine beetle in Atlantic coastal and piedmont regions. For Sci 30: 143-156.

Michaels PJ, Sappington DE, Spengler PJ, Phillip J (1986) SPBCMP-A program to assess the likelihood of major changes in the distribution of southern pine beetle infestations. S J Appl For 10:158-161

Mitchell JFB ( 1989) The greenhouse effect and climate change. Rev Geophys 27( 1): 115139.

Nikolov NT, Zeller KF (1992) A solar radiation algorithm for ecosystem dynamic models. Ecol Model 61:149-168.

Price PW ( 1991) The plant vigor hypothesis and herbivore attack. Oikos 62:244-251.

Price TS. Doggett C (1982) A history of southern pine beetle outbreaks in the southeastern United States. GA For Comm, Macon, GA.

Price TS. Doggett C. Pye JM, Holmes TP (1992) A history of southern pine beetle outbreaks in the southeastern United States. GA For Comm, Macon, GA.

Pritchett WL ( 1979) Properties and management of forest soils. John Wiley and Sons, New York.

Reeve JD, Ayres MP. Lorio PL Jr (1995) Host suitability, predation, and bark beetle population dynamics. In Cappuccino N. Price $\mathrm{P}$ (Eds) Population dynamics. Academic Publishers, New York. 
Rhodes DF (1979) Evolution of plant chemical defense against herbivores. In Rosenthal GA, Janzen DH (Eds) Herbivores: Their interaction with secondary plant metabolites. Academic Press, New York.

St George RA ( 1930) Drought-affected and injured trees attractive to bark beetles. J Econ Entomol 59:955-957.

Schlesinger ME. Zhao ZC ( 1989) Seasonal climatic change introduced by doubled $\mathrm{CO}_{2}$ as simulated by the OSU atmospheric GCM/mixed-layer ocean model. J Climate 2:429495.

Strain BR, Higgmbotham KO, Mulroy JC (1976) Temperature preconditioning and photosynthetic capacity of Pinus taeda L. Photosyn 10:47-53.

Swain KM, Remoin MC ( 198 I) Direct control methods for the southern pine beetle. USDA Agric Handbook 575: 15.

Turchin P. Lorio PL Jr. Taylor AD, Billings RF (1991) Why do populations of southern pine beetle (Coleoptera: Scolytidae) fluctuate? Environ Entom 20:401-409.

Waring GL, Cobb NS (1992) The impact of plant stress on herbivore population dynamics. In Bemays EA (Ed) Plant-insect interactions. CRC Press, Boca Raton, FL.

White TCR ( 1974) A hypothesis to explain outbreaks of looper catepillars, with special reference to populations of Selidosema suavis in a plantatiion of Pinus radiata in New Zealand. Oecologia, 16:279-301.

Wyman L (1924) Bark-beetle epidemics and rainfall deficiency. USDA For Ser Bull 8:2-3. 